\title{
Behind the paper: muzzling muscle spasticity
}

In September 2008, Kendall Winter was driving to a friend's house along Highway 20 in central Alberta when her silver, compact Chevrolet slipped onto the shoulder of the road. Her car rolled six times, and she found herself trapped in the mangled wreckage, but still conscious.

After being pulled from the remains of her car, Winter, then 19 years old and working as a house painter, realized she was almost completely paralyzed from the neck down; she could move her arms but had lost sensation in her hands and legs. To make matters worse, within a few months she started experiencing intense, involuntary muscle spasms ranging from clenched fists to uncontrolled leg kicking.

To ease the pain, Winter was prescribed baclofen, the leading drug used to treat spinal cord injury-associated spasticity. The medication, however, came with side effects, including excessive drowsiness, which meant that Winter had to strike a delicate balance between controlling her spasms and being mobile. Because of the downside to baclofen, a derivative of gamma-aminobutyric acid (GABA), researchers have been on the lookout for alternatives to it for decades.

One promising early candidate was cyproheptadine, which targets the serotonin receptor. Cyproheptadine was shown nearly 30 years ago to reduce spasticity and enhance locomotor function in spinal cord-injured patients ${ }^{1}$, yet the drug fell out of favor because it led to increased food intake and weight gain. Nonetheless, many researchers maintained that cyproheptadine was as effective or more effective than baclofen for spasticity. "I have always felt that [cyproheptadine] was a very useful pharmaceutical," says Patricia Nance, a rehab physician at the Veteran Affairs Health Center-Long Beach in California.

Aside from the unwanted side effects, an added problem with cyproheptadine has been that no one understood how the drug really works. Cyproheptadine's primary mode of action is to block serotonin receptors, yet no serotonin-producing neurons travel through the spinal cord below the site of injury in quadriplegics and paraplegics.

To explain the mechanism, a team led by neuroscientist David Bennett at the University of Alberta in Edmonton turned to a rat model of spinal cord injury. In this issue of Nature Medicine, Bennett and his colleagues show that the serotonin receptors in the lower

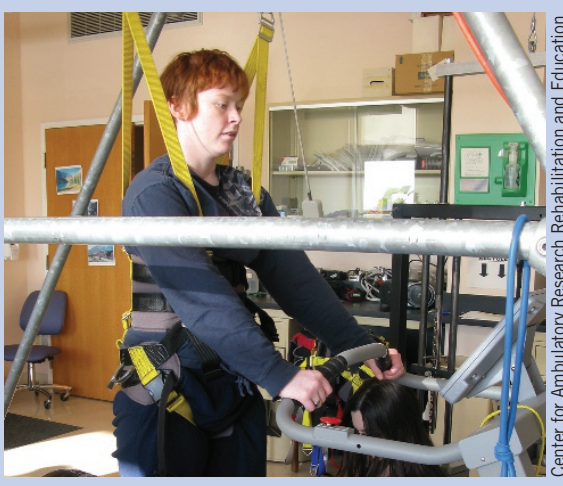

Stepping up: Kendall Winter in rehab.

spine become reactivated after injury, even though there are no serotonin-producing neurons below the site of spinal transection ${ }^{2}$. The researchers found that cyproheptadine silenced the receptors and eased spasms in rats with severed spinal cords.

"It completely flies in the face of what we know of a receptor," says Bennett. "A receptor is supposed to receive by definition. The analogy would be a telephone starting to talk without anyone talking into it."

Bennett suspects that this peculiar feature of constitutive activity serves as a natural safeguard against injury and disease. Because some serotonin receptor activity is necessary for recovery after spinal cord trauma, the receptors compensate for the lack of signal by switching on in the absence of serotonin to enable movement. But this overactivation can also tweak motor neurons to produce muscle spasms.

Bennett's wife and frequent collaborator, neurophysiologist Monica Gorassini, immediately realized that the discovery in rats could explain why cyproheptadine also protects humans from debilitating spasms. To confirm her hunch, starting in April 2009 , Gorassini began to enlist people with varying degrees of spinal cord injury from her University of Alberta clinic to take part in a small, one-day trial with the drug.

One of the seven participants was Winter, who, by 20 August when she took part in the trial, had regained motor control throughout most of her body and was walking again. (She still has no feeling in her right hand.) Four times each day she would take baclofen, but on the day of the trial she substituted a single dose of cyproheptadine. "Within an hour of taking the cyproheptadine," Winter recalls, "I was having basically no spasms and I was noticing no side effects - no drowsiness — and it lasted well into the evening."
Tom Russell, a 52-year-old writer with the Blood Tribe First Nations of southwestern Alberta also took part in the study. Although he does not regularly take any medication, Russell has experienced spasms since becoming paralyzed in a car accident more than 30 years ago. At first, cyproheptadine made him drowsy for several hours, recalls Russell, but his spasms subsided for close to 48 hours after taking the drug. "I could move my fingers and walk around without my legs twitching," he says. "Those two days were pretty good. I really enjoyed it. It's just the side effects I didn't like."

Gorassini conducted reflex tests analogous to the ones that Bennett had performed in the animal model. "By doing the parallel experiments that we did in the rats in the humans, we know where the cyproheptadine is working, and it's working in the motor neurons," Gorassini says.

Gorassini says the study should stimulate other researchers to find agents that block serotonin but don't have broad side effects on appetite and the rest of the body. But Jay Meythaler, a spinal cord injury researcher at Wayne State University in Detroit who was not involved in the study, remains skeptical. "While I may grant that serotonin plays a role, I am not convinced [that the motor neurons] become self activating without the presence of serotonin, as the authors assume there are not other inhibitory or excitatory pathways at work," he says.

Bennett agrees that other factors, such as the GABA pathway, also contribute to spasticity. But he argues that the serotonin receptors are switched over to a more constitutively active isoform after injury. "These receptors are truly activated on their own," he says. As such, jamming these receptors will be an effective means of blocking this part of the spasticity pathway.

Regardless of the mechanism, Winter says she's considering adopting cyproheptadine full time. "It seemed to work better than my baclofen did, with more lasting effects," says Winter, now a pre-med student at Red Deer College in Red Deer, Alberta. Although she's nervous about the arduous process of finding the right dosage, "for me, it would be worth the switch."-Elie Dolgin

1. Barbeau, H., Richards, C.L. \& Bédard, P.J. J. Neurol. Neurosurg. Psychiatry 45, 923-926 (1982).

2. Murray, K.C. et al. Nat. Med. 16, 694-700 (2010).

Published online: 30 May 2010; doi: $10.1038 / \mathrm{nm} .2169$ 